\title{
No le perdono a la Muerte esta muerte
}

Waldo Ansaldi ${ }^{1}$

Tenía nombre imperial. No recuerdo si sus padres, inmigrantes croatas, se lo pusieron en relación a su homónimo, Emperador de Austria y rey de Hungría, Bohemia, Croacia y Eslavonia, Dalmacia, Galitzia, Lodomeria e Iliria. También lo conocíamos usualmente como Gringo y Polaco. Algunos pocos, amigos peruanos, si no recuerdo mal, le llamaban Pancho, y, obviamente, nadie Pepe. Yo le llamé, siempre, Gringo. Nunca de otra manera.

Hay muchos modos de recordar y homenajear a cualquier persona de actuación destacada. En este caso, mi recordatorio del Gringo Delich no puede obviar la historia de las relaciones personales entre ambos. Lo conocí en 1961, cuando yo terminaba la escuela secundaria y él formó parte de un ciclo de exposiciones de profesionales dispuesto por las autoridades del colegio para que tuviéramos más elementos de juicio para decidir la elección de una carrera universitaria. Sus charlas se referían, obviamente, a la abogacía, carrera de la cual él había egresado poco antes. Mi vocación eran las ciencias sociales, pero mi elección -más bien pragmática, mas no exenta de posicionamiento- fue la abogacía. Por entonces, en Córdoba no había carreras de Sociología o Ciencia Política, y el campo del Derecho era tan amplio, profesionalmente, que además de ser abogado se podía ejercer como periodista, profesor, historiador, político, etc. Hicimos muy buenas migas desde el comienzo, supongo que acrecentadas, entre otras cosas, por el hecho de ser ambos militantes estudiantiles con muchos puntos de coincidencias. Recuerdo que me dio una tarjeta personal de recomendación para un profesor de primer año -que nunca utilicé- donde, además, indicaba que no valía para el momento del examen.

Cursé tres años de abogacía, tiempo que coincidió con su estancia en París para formarse en el campo de la Sociología. A su regreso, poco después de mi ingreso a la carrera de Historia, reiniciamos rápidamente nuestro relacionamiento, marcado por una ambigüedad que se manten-

${ }^{1}$ Investigador Principal del Consejo Nacional de Investigaciones Científicas y Técnicas (CONICET). 
dría hasta su muerte: ambos estábamos en el mismo bando pirata en el fútbol cordobés, pero en el de Buenos Aires nos enfrentábamos, cuervo él, diablo, yo.

Aprendí de él una primera gran enseñanza por la que le debo mucho: saber pensar sociológicamente. Hice todos sus cursos extracurriculares de Sociología del Trabajo en la Facultad de Derecho, donde discutíamos y cuestionábamos el estructural-funcionalismo y analizábamos el formidable debate que por entonces atravesaba el marxismo. El Gringo venía de estudiar con Henry Lefebvre, a quien yo ya había leído, de modo que las conversaciones con él me ayudaron a comprender mejor a este gran pensador francés. Asimismo, conocí la obra de Alain Touraine, por entonces poco conocido en Argentina, salvo para algunos sociólogos de Buenos Aires. El Touraine de esos años era un estímulo para pensar las mejores maneras de analizar la acción social, las clases y luego los movimientos.

En 1966 me convocó para ser parte del equipo que investigó la economía del azúcar en Tucumán, Salta y Jujuy y, por añadidura, me confió la jefatura de trabajo de campo para el área cañera. Fue una experiencia formidable, en un momento álgido de la historia de la sociedad argentina. La investigación tenía una dirección tripartita: Delich, Silvia Sigal y Miguel Murmis, a quienes conocí entonces. Dicho sea de paso, de Miguel aprendí otras cosas y pude valorar, sobre todo, su enorme calidad humana. Uno de los resultados de esa investigación fue la tesis doctoral del Gringo, que presentó y defendió en la Facultad de Derecho de la UNC, luego transformada en ese excelente libro que fue -y sigue siendo- Tierra y conciencia campesina en Tucumán (1970). Es un interesante ejercicio leerlo -releerloen paralelo y simultáneamente con Crisis y protesta social. Córdoba, 1969, un trabajo modélico de análisis crítico de una coyuntura, un hecho y un proceso en curso. Tuve mucho que ver con la escritura de esos dos libros, en conversaciones que aumentaron mi interés por pensar sociológicamente. Como al mismo tiempo iba adquiriendo una muy buena formación historiográfica crítica filiada en la llamada Escuela de los Annalesy en la historia social británica - de la mano de Aníbal Arcondo, Guillermo Beato, Oscar del Barco y Ceferino Garzón Maceda, como también de las por entonces jóvenes Hilda Iparraguirre y Ofelia Pianetto-, encuentro allí el germen de mi posterior proceso de analizar y explicar los procesos sociohistóricoscríticamente, en la larga duración e hibridando fragmentos de disciplinas. Mirado desde muchos años más tarde, en ese germen el aporte del Gringo fue central, como también el de Pancho Aricó, con quien ahondé mis conocimientos de la obra de Antonio Gramsci. 
Digo que el aporte de Delich fue central para mí, porque me permitió la rara experiencia de aprender a investigar en el campo de la sociología antes que en dela historiografía, la carrera que cursaba formalmente.

En 1974 me convocó para desempeñarme como profesor en el primer Curso Avanzado de Sociología Rural Latinoamericana, un posgrado itinerante organizado por el Consejo Latinoamericano de Ciencias Sociales (CLACSO), que se llevó adelante en Asunción. Tuvo tres convocatorias más, con concreción en Quito, San José y Santo Domingo) y, por cierto, directores distintos. En el duro y difícil 1976 sugirió mi nombre para desempeñarme en la segunda edición de ese Curso y luego en el proyectado Programa de Estudos Comparados Latinoamericanos (Universidade Federal de Minas Gerais), pero por diferentes razones, ajenas a él, no se concretaron. Así fue como, a principios de 1977, me invitó a ser Asistente Especial de la Secretaría Ejecutiva de CLACSO, cuya titularidad él había, asumido, con valentía. Los años que compartimos mientras el Gringo tuvo la dirección del Consejo, hasta fines de 1983, fueron muy intensos por diferentes motivos, y acrecentaron, por el trabajo cotidiano en un contexto político más que desfavorable (para decirlo delicadamente), no sólo en Argentina, nuestra amistad. Delich impulsó varios proyectos e iniciativas para el mundo de las ciencias sociales latinoamericanas. Destaco, en particular, 1) los dos Programas de AsistenciaAcadémica (uno individual, el otro, para equipos) dedicados a atender las necesidades de los colegas cesanteados y/o detenidos por razones políticas o ideológicas en los países sometidos a dictaduras; estos Programas fueron notabilísimos y sirvieron para uno posterior impulsado por las Universidades centroamericanas; 2) el fortalecimiento de los programas de posgrados latinoamericanos, una saga que había iniciado años antes Jorge Graciarena; 3) el lanzamiento de la Biblioteca de Ciencias Sociales, una colección de libros cuya dirección confió al querido y tempranamente fallecido Mario dos Santos; 4) la convocatoria a la Conferencia Regional sobre las condiciones sociales de la democracia en América Latina, realizada en San José de Costa Rica en octubre de 1978, punto de partida del debate sobre la democracia en Nuestra América, debate que se prolonga hasta hoy. Un mojón más fue el seminario sobre Dictaduras y dictadores en América Latina, realizado en 1980 en México DF, apuntando, en este caso, a algunos prototipos particulares, personalizados, en una clave historiográfica y científico-política. Sinhipérbole alguna: el Gringo fue el padre del análisis de la cuestión de la democracia en América Latina -sin desmedro de los pioneros trabajos de Pablo González Casanova y Norbert Lechner sobre México y Chile, respectiva- 
mente-, planteada en pleno desarrollo de dictaduras institucionales de las Fuerzas Armadas y de Estados Terroristas de Seguridad Nacional.

El debate sobre la democracia se expresó y continuó luego en Crítica \& Utopía. Latinoamericana de Ciencias Sociales, cuyo primer número apareció en 1978. La revista, a menudo considerada publicación del Consejo, en realidad fue un proyecto editorial pergeñado por el Gringo, que fue su director, al mismo tiempo que Secretario Ejecutivo de CLACSO, de donde la confusión, incrementada por la constitución del Consejo Académico y los autores de buena parte de los artículos. Institucionalmente, en rigor, la revista era responsabilidad de un pequeño grupo de personas que en Buenos Aires formamos a tal efecto una asociación civil de igual nombre, cuyo objetivo principal era, justamente, la edición de la revista.Crítica \& Utopía fue -sigue siendo- referencia obligada para dicho debate, aunque también estuvo abierta al planteo de varias otras cuestiones. Si como proyecto político-cultural-académico fue más que importante y fue una manifestación más de la agudeza y el compromiso de Delich, quiero destacar una realización más modesta: la de David y Goliath. En 1980 decidimos cambiarle «la cara al viejo Boletín de Clacso, pero manteniendo el espíritu con el que fue creado», el de ser uno de los pocos si no único vehículo de comunicación de y entre los científicos sociales latinoamericanos. La ruptura en la continuidad (por ésta, el primer número de la revista fue el 38-39), que expresaba la redefinida publicación, no sólo era por la superioridad cualitativa. Quiero rescatar la presentación que el Gringo escribió entonces, porque ese breve texto, claro, preciso, lúcido, comprometido, valiente, lo definía al autor como pocos otros. Tengo para mí que fue el mejor texto, el más bello, que escribió. Téngase muy en cuenta el tiempo y el espacio: 1980, Buenos Aires, dictaduras por doquier.Permítaseme la larga cita y eximirme de comentarla, pues, creo, habla por sí misma:

David y Goliath es la metáfora de un combate desigual, el de la fuerza y la razón. El imprevisto triunfo de la razón se debe sin duda a una excepcional puntería reunida con alguna dosis de azar, suponiendo, claro está, que el combate efectivamente tuvo lugar. Hay que suponer -porque no tenemos precisiones- que la fuerza estaba llena de sí misma, mientras que la razón disponía de una honda. También que, además de la puntería, la razón obró con notable rapidez. Es cierto que en la era tecnotrónica una honda no es demasiado, pero no es irrelevante frente a un enemigo muy armado pero desnudo, porque tal vez el secreto del éxito no esté tanto en el instrumento como en la puntería. 
Fuerza y razón son dos constantes de nuestra historia latinoamericana. A veces, la razón se disfraza en la razón de la sinrazón, en el irracionalismo, otras, en la pura no razón, y en ambos casos los pueblos terminan pagando. Pero no siempre la razón coincide consigo misma, no siempre la razón se asume como fuerza intrínseca y también los pueblos pagan los errores de esta razón extraviada. Constantes pero no determinantes..., la lógica de esta vieja confrontación necesariamente marca la práctica de los científicos sociales en particular y de los intelectuales en general, se expresa en la pertinencia o impertinencia temática, en los criterios de verdad, en la medida del buen uso teórico. Es en el interior de esta relación desigual y no en un espacio vacío donde se define y debe definirsenuestro trabajo.

Todavía prosigue el combate de David y Goliath porque - hèlas - ninguna pedrada es capaz de concluir con esta historia que estamos contando y que seguiremos contando y construyendo hasta donde podamos. Nuestra modesta responsabilidad nos obliga a perseverar, dejando para otros tiempos el desaliento y el crepúsculo. Por eso David y Goliath se difunde desde Buenos Aires.

Después, ya en democracia, seguimos, básicamente por razones laborales, caminos diferentes, a veces paralelos, en ocasiones, cruzados, otras divergentes. Ya no nos veíamos con la asiduidad cotidiana, compartiendo trabajo y encuentros fuera de éste. Más recientemente, su deambular político, desconcertante e inexplicable para mí, ahondó la distancia, pero nunca -porque el Gringo jamás dejó de ser un agudo sociólogo, un lúcido analista de las sociedades (pero eso el desconcierto era mayor)- nos convirtió en enemigos o adversarios. Aun discrepando fuertemente, yo no podía poner estas diferencias por encima de cuánto significó en mi vida. Por lo demás, en materia de derechos fundamentales, los argentinos no deberíamos olvidar que fue por su iniciativa que los constituyentes de 1994 incluyeron el derecho de habeas data en nuestra Carta fundamental.

Es cierto, no era fácil trabajar con él, pero supimos hacer de las diferencias de estilo un modus operandi efectivo. El Gringo me enseñó a pensar sociológicamente, me brindó un espacio de trabajo en un momento crucial, trabajo que me permitió relacionarme con numerosísimos colegas latinoamericanos y, sobre todo, a recorrer y conocer Nuestra América. Y a la hora de un balance estrictamente personal, no puedo dejar de señalar su fortísima solidaridad cuando el terrible momento de la muerte de mi primera hija. Eso solo habría sido suficiente para guardarle afecto perenne. 
Tanto dolor se agrupa en mi costado, que por doler me duele hasta el aliento.

Un manotazo duro, un golpe helado, un hachazo invisible y bomicida, un empujón brutal te ha derribado.

(Miguel Hernández, Elegía a Ramón Sijé).

Sí, yo no le perdono a la Muerte, esta muerte. Y a las lectoras y lectores sí les pido me perdonen si este texto es demasiado autorreferencial. Es que, sinceramente, no puedo recordar a Francisco José Delich si no es desde esta vereda personalísima.

Por todo, gracias querido Gringo, doquiera que estés, supuesto que después de muertos estamos en algún lugar diferente al de la memoria de los que nos sobreviven. 